\title{
Impact Analysis of Headway Distribution on Single Lane Roundabout Entry Capacity
}

\author{
Liang $\operatorname{Ren}^{1}$ and Xiaobo $Q \mathbf{u}^{2}$
}

\begin{abstract}
The Highway Capacity Manual (referred to as the HCM hereafter) 2000 model estimates roundabout entry capacity under an assumption of circulating headways following an exponential distribution. However, some studies indicated that the HCM 2000 model could over- or under-estimate entry capacity. This situation might be attributed to an unfit assumption of headway distribution type. Therefore, this study begins with analysis of headway distributions based on field survey. This study firstly indicates that the inverse Gaussian distribution is the best fitted distribution type of headway samples. According to this finding, we thus intend to adjust the HCM 2000 model. To this end, we propose a simulation based approach to estimate entry capacity of single-lane roundabouts. A linear relationship is established to represent the relationship between a capacity ratio of the simulation-based approach to the HCM 2000 model and conflicting flow. The linear function can be considered as a coefficient of the HCM 2000 model. It is believed that the modified HCM 2000 model outperforms the HCM 2000 model.
\end{abstract}

Keywords: headway distribution type analysis, modified HCM 2000 model, roundabout entry capacity.

\section{Introduction}

A roundabout is a type of circular intersection with one or more marked lanes in which road traffic is slowed and flows almost continuously in one direction around a central island to several exits onto the various intersecting roads (Hellinga and Sindi, 2012; Qu et al., 2014a). The early roundabouts are proposed a gyratory traffic scheme (i.e. one way circulation around a central island) (Qiu and Yin, 2011). Along with increase of traffic volume modern roundabouts are designed and established to satisfy higher requirements of safety, capacity and fluidity (Turner et al., 2011). Modern roundabouts have successfully implemented in Europe, Australia and the United States (Kittleson and Associates, 2011). Nowadays, roundabouts have been an increasingly popular intersection type, especially in less populous suburbs. In general, roundabouts substantially reduce queue and delay under low volume conditions as vehicles are not required to perform a complete stop. Roundabouts allow Uturn within the normal flow of traffic, which are often difficult to implement at other forms of junction (Flannery, 2011). Further, roundabouts provide higher safety than signal controlled junctions in terms of not only frequency but also severity of accidents. Fortuijn (2009) asserted that as the vehicles in a roundabout could drive along the same direction, the probability of crashes could be reduced thanks to the decrease of conflicting points. Along

$1 \quad$ High Degree Research Student, School of Engineering, Griffith University, Room 2.24, G39, Griffith University, Gold Coast, QLD 4222, Australia , Tel: +61-7-755527608, Fax: +61-7-755528065, Email: 1.ren@griffith.edu.au.

2 Senior Lecturer, School of Engineering, Griffith University, Room 1.17, G09, Girffith University, Gold Coast, QLD 4222, Australia, Tel: +61-7-55529724, Fax: +61-7-55528065, E-mail:

x.qu@griffith.edu.au. 
with the wider use of roundabouts, the entry capacity is of more importance to transport agencies (Bared and Afshar, 2009; Wei and Grenard, 2011).

Various models have been developed to estimate the entry capacities of roundabouts (Bie et al., 2012; Diah et al., 2011; Wong, 1996). Highway Capacity Manual (HCM) 2000 model is the most widely-used analytical model based on the gap acceptance theory (TRB, 2000), mathematically,

$$
C_{2000}=v_{c} \times \frac{\exp \left(-v_{c} \tau_{c} / 3600\right)}{1-\exp \left(-v_{c} \tau_{f} / 3600\right)}
$$

where $C_{2000}$ is the entry capacity of an arm (veh/hr); $v_{c}$ is the conflicting circulating flow (veh/hr); $\tau_{c}$ and $\tau_{f}$ are critical gap and follow-up time (sec), respectively.

In the above-mentioned model, the entry capacity is calculated as a function of conflicting circulating flow, critical gap, and follow-up time. Additionally, the HCM 2000 model assumes that the circulating headways follow an exponential distribution (Polus et al., 2003; Wei and Grenard, 2012). However, some studies indicated that the HCM 2000 model may under- or over-estimate roundabout capacity (Mereszczak et al., 2006), and a relative error does exist in the HCM 2000 model (Cowan, 1997). Based on our research, follow-up time is possible to be measured from field survey. Furthermore, as critical gap cannot be observed directly, many feasible methods have been developed for its estimation from observed rejected and accepted gaps, such as those of Siegloch (1973), Raff (1950), Harder (1968) and $\mathrm{Wu}$ (2012). Accordingly, we conjecture that the relative error can be explained by an unrealistic assumption of headway distribution type. Hence, we intend to analyse impact of headway distribution type. To this end, this study begins with confirming a best fitted distribution type that circulating headways follow. Based on the accrual distribution types, we are able to modify the HCM 2000. In this study, we observed nine roundabouts (one hour per roundabout) to collect field survey data.

\section{Data Collection}

Based on field survey, nine roundabouts located in Gold Coast QLD, Australia are used to collect circulating headways, critical gaps and follow-up times at peak.

\section{Headway}

Headway is a time gap between two consecutive vehicles in circulating stream (Isebrand and Hallmark, 2012). As can be seen in Figure 1, headways are counted as time difference between two consecutive vehicles passing the red line. 


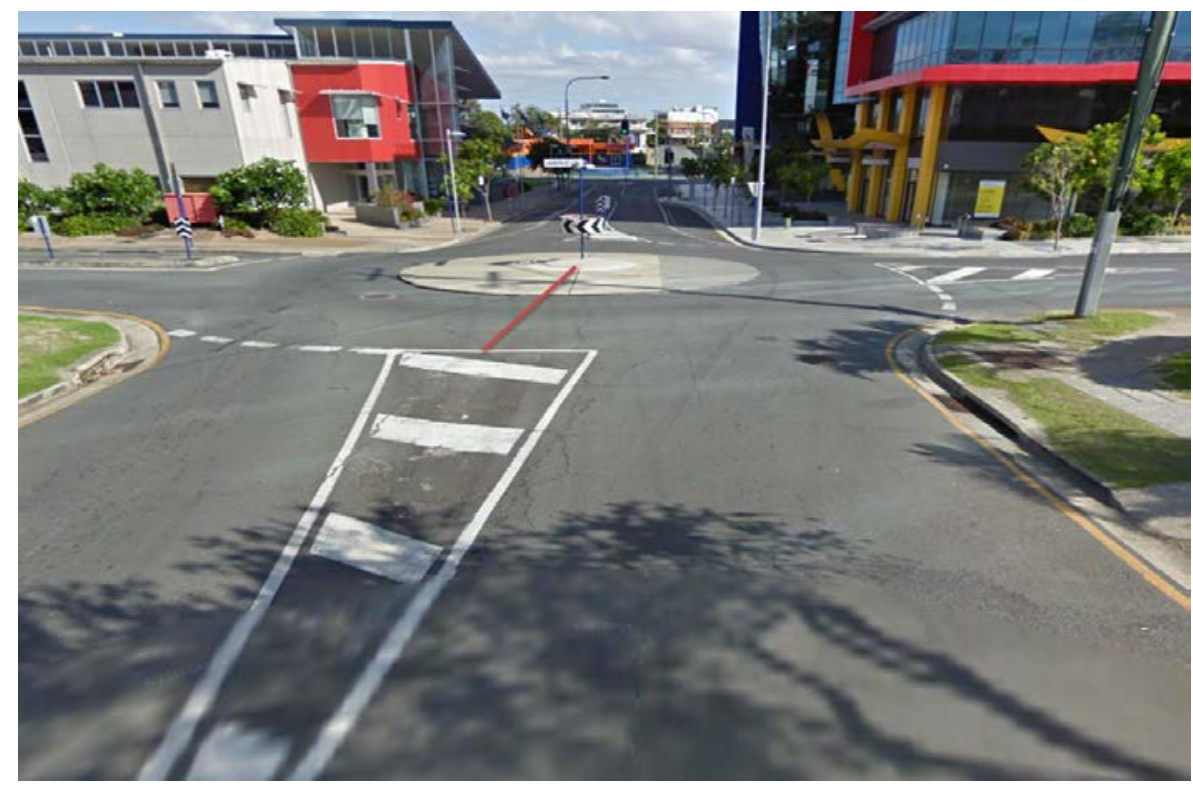

Figure 1. A roundabout

\section{Critical gap}

The critical gap is estimated using the distributions of gap acceptance and rejection data. The methods commonly used for estimating the critical gap include the graphical method (Flannery and Datta, 1997; Siegloch, 1973), the maximum likelihood method (Harders, 1968; Raff and Hart, 1950; Troutbeck, 1992) and the probability equilibrium method (Wu, 2012). The graphical method is used in this study. The critical gaps are found to range from 4.32sec to $4.82 \mathrm{sec}$.

\section{Follow-up Time}

In this study, all follow-up times are measured from each roundabout. The follow-up time is then calibrated by taking a mean value of all measured follow-up times for each roundabout. They range between $2.35 \mathrm{sec}$ and $2.75 \mathrm{sec}$.

\section{Headway Distribution Type Analysis}

As mentioned in introductory section, this study intends to analyse the distribution type of headways following. To this end, an engineering program, BestFit, is used to compare the histogram of headway samples and the probability of density function (PDF) of the exponential distribution. We then apply a Kolmogorov-Smirnov test (K-S test) to check whether headway samples follow an exponential distribution. The K-S test is a nonparametric test for the equality of continuous, one-dimensional probability distributions that can be used to compare a sample with a reference probability distribution (Jin et al., 2011; Meng and Qu, 2012; Qu et al., 2015; Qu and Meng, 2014). According to results from the BestFit and the K-S test, the majority of headway samples follow an inverse Gaussian distribution. In other words, inverse Gaussian distribution could be the best fitted distribution type of circulating headways following. The assumption of HCM 2000 model is not valid.

\section{Model Improvement}

As mentioned in the previous section, in most cases, the circulating headways do not follow exponential distributions. However, the HCM 2000 model provides an analytical solution to estimate roundabout entry capacity under an exponentially distributed assumption. In this study, we propose a simulation framework to estimate the entry capacities by taking into account the actual headway distributions. 


\section{Simulation Model}

In this study, a simulation model is developed based on gap acceptance theory. According to drivers' decision making process, the number of vehicles being able to enter a roundabout could be formulated by

$$
N=\left\{\begin{array}{l}
0, \text { if } T<\tau_{c} \\
i, \text { if } \tau_{c}+(i-1) \tau_{f} \leq T<\tau_{c}+i \tau_{f}
\end{array}\right.
$$

where $T$ is a time gap (headway) within circulating stream. Based on our field survey, various lengths of circulating headways are recorded for each roundabout. According to their corresponding calibrated critical gaps and follow-up times, the entry capacities for each roundabout can be estimated by summing numbers of vehicles being able to enter all headways in an hour. An example of the simulation is shown in Table 1. In the example, the calibrated critical gap and follow-up time are $4.61 \mathrm{sec}$ and $2.39 \mathrm{sec}$, respectively.

Table 1. An example of the simulation

\begin{tabular}{ccccc}
\hline $\begin{array}{c}\text { Cumulative } \\
\text { time (sec) }\end{array}$ & $\begin{array}{c}\text { Headways, } \\
T(\mathrm{sec})\end{array}$ & $\begin{array}{c}\text { Simulated No. of } \\
\text { vehicles entering, } N\end{array}$ & $\begin{array}{c}\text { No. of } \\
\text { headways, } n\end{array}$ & $\begin{array}{c}\text { Simulated Capacity } \\
\text { (veh/hr) }\end{array}$ \\
\hline 0 & 0 & 0 & 0 & 1248 \\
23.273 & 23.273 & 8 & 1 & \\
58.363 & 35.09 & 13 & 2 & \\
59.937 & 1.574 & 0 & 3 & \\
68.212 & 8.275 & 2 & 4 & \\
71.475 & 3.263 & 0 & 5 & \\
78.018 & 6.543 & 1 & 6 & \\
92.302 & 14.284 & 5 & 7 & \\
108.758 & 16.456 & 5 & 8 & \\
146.738 & 37.98 & 14 & 9 & \\
158.907 & 12.169 & 4 & 10 & \\
202.453 & 43.546 & 17 & 11 & \\
$\ldots$ & $\ldots$ & $\ldots$ & 257 & \\
3596.479 & 12.458 & 4 & 258 & \\
3600.024 & 3.545 & 0 & & \\
\hline
\end{tabular}

Notes: Headway $=$ cumulative time $_{n}-$ cumulative time $_{n-1}, \forall n \in(1,258)$

Conflicting flow, $v_{c}=$ No. of headways $(258 \mathrm{veh} / \mathrm{hr}$ )

Simulated capacity $=\sum_{n=1}^{n=258} N$

Similarly, the entry capacities for the other eight roundabouts are estimated, ranging from 514 to $1248 \mathrm{veh} / \mathrm{hr}$.

A Comparison between the Results from the Simulation Model and HCM 2000 Model To modify the HCM 2000 model, we establish a linear function as a coefficient based on a regression analysis. In this study, all data for the regression analysis, including critical gaps, 
follow-up times and conflicting flows, are collected from nine observed roundabouts. For establishing the linear function, the following procedure is recommended:

1. Calibrate conflicting flow for one roundabout using the introduced simulated method in Table 1.

2. Based on its calibrated critical gap and follow-up time and conflicting flow, calculate entry capacity according to the HCM 2000 model using Eqn. (1).

3. Estimate entry capacity according to the simulation in Table 1.

4. Calculate a capacity ratio of the simulation to the HCM 2000 model.

5. Repeat step 1 to 4 and calculate capacity ratios for all nine observed roundabouts. Capacity ratios are shown in Table 2.

According to nine capacity ratios, establish a linear function which is shown in Figure 2. 
Table 2. HCM 2000 model calibration and validation

\begin{tabular}{|c|c|c|c|c|c|c|c|c|c|c|}
\hline \multirow{2}{*}{$\begin{array}{l}\text { Roundabout } \\
\text { (i) }\end{array}$} & \multirow{2}{*}{$\begin{array}{c}\text { Conflicting } \\
\text { flow } \\
\text { (veh/hr) }\end{array}$} & \multicolumn{2}{|c|}{ Capacity (veh/hr) } & \multirow{2}{*}{$\begin{array}{c}\text { Ratio } \\
\text { (Simulation/HCM) }\end{array}$} & \multirow{2}{*}{$\begin{array}{l}\text { Calibrated } \\
\text { ratio }\end{array}$} & \multirow{2}{*}{$\begin{array}{c}\text { Modified HCM } \\
\text { capacity } \\
\text { (veh/hr) }\end{array}$} & \multicolumn{2}{|c|}{ Relative error (\%) } & \multicolumn{2}{|c|}{ RMSD } \\
\hline & & Simulation & $\begin{array}{l}\mathrm{HCM} \\
2000 \\
\end{array}$ & & & & $\begin{array}{l}\text { HCM } \\
2000 \\
\end{array}$ & $\begin{array}{l}\text { Modified } \\
\text { HCM }\end{array}$ & $\begin{array}{l}\text { HCM } \\
2000 \\
\end{array}$ & $\begin{array}{l}\text { Modified } \\
\text { HCM }\end{array}$ \\
\hline 1 & 249 & 1202 & 1208 & 0.9950 & 1.0069 & 1216 & 4.66 & 0.92 & 48.17 & 12.79 \\
\hline 2 & 220 & 1248 & 1222 & 1.0213 & 1.0185 & 1245 & & & & \\
\hline 3 & 258 & 1150 & 1135 & 1.0132 & 1.0033 & 1139 & & & & \\
\hline 4 & 291 & 1099 & 1081 & 1.0167 & 0.9901 & 1070 & & & & \\
\hline 5 & 744 & 514 & 634 & 0.8107 & 0.8089 & 513 & & & & \\
\hline 6 & 378 & 968 & 1014 & 0.9546 & 0.9553 & 969 & & & & \\
\hline 7 & 409 & 924 & 972 & 0.9506 & 0.9429 & 916 & & & & \\
\hline 8 & 310 & 1002 & 1030 & 0.9728 & 0.9825 & 1012 & & & & \\
\hline 9 & 248 & 1113 & 1117 & 0.9964 & 1.0073 & 1125 & & & & \\
\hline
\end{tabular}

Notes: Calibrated ratio $=-0.0004 v_{c}+1.1065$

Modified HCM capacity = Calibrated ratio $\times$ HCM 2000

Relative error $\mathrm{HCM} \mathrm{2000}=100 \% \times\left(\sum_{i=1}^{i=9}\left|\frac{\mathrm{HCM} 2000_{i}-\text { Simulation }_{i}}{\text { Simulation }_{i}}\right|\right) / 9$

Relative error $\mathrm{Modified} \mathrm{HCM}=100 \% \times\left(\sum_{i=1}^{i=9}\left|\frac{\text { Modified } \mathrm{HCM}_{i}-\text { Simulation }_{i}}{\text { Simulation }_{i}}\right|\right) / 9$

RMSD is root-mean-square deviation

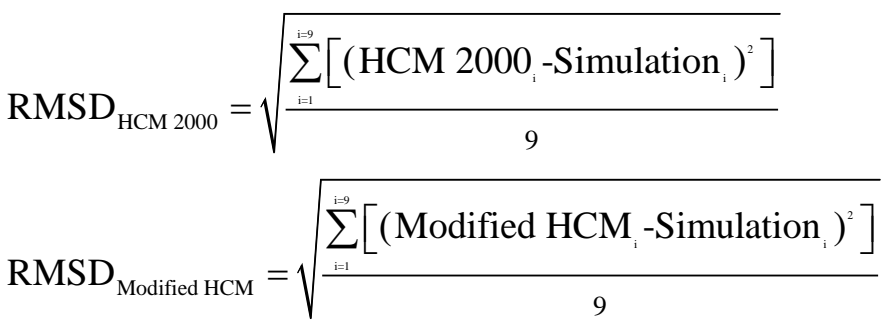




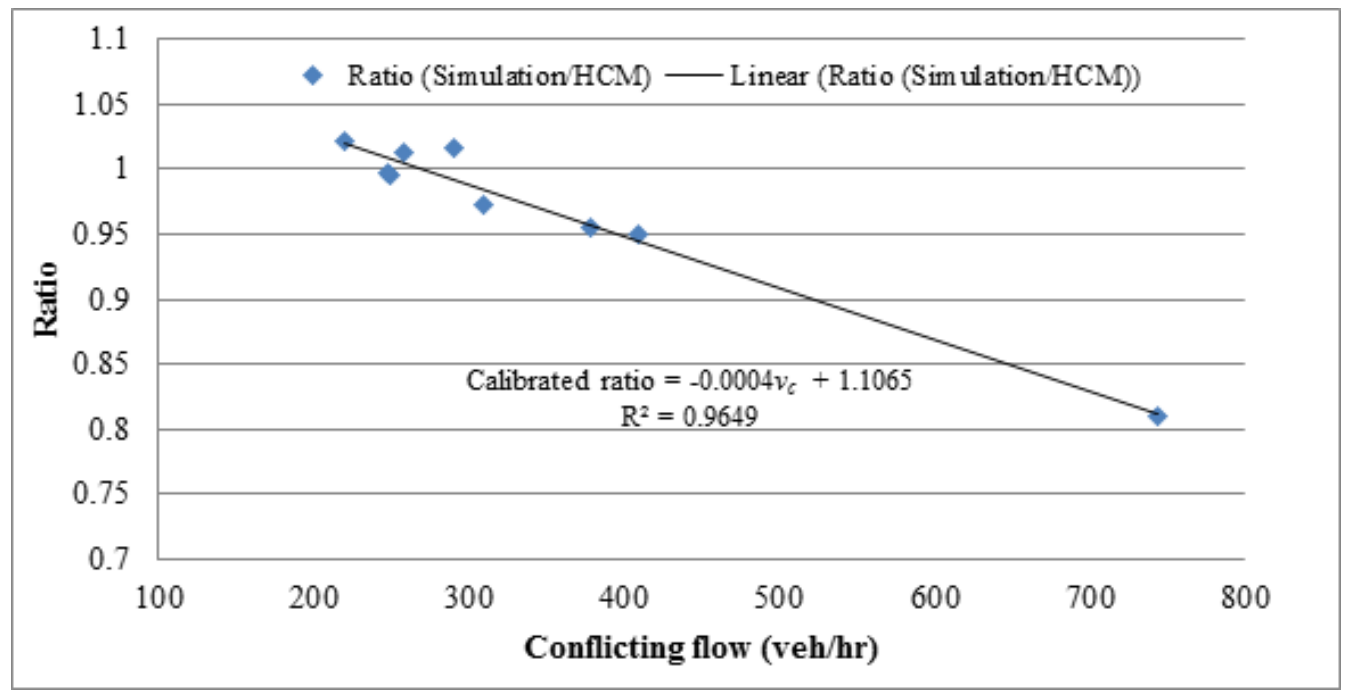

Figure 2. Trendline of capacity ratio

As can be seen in Figure 2, a linear trendline is found to show the relationship between the capacity ratio of the simulation to the HCM 2000 model and conflicting flow. The linear trendline represents a function to modify the HCM 2000 model as follows:

$$
\text { Calibrated ratio }=-0.0004 v_{c}+1.1065
$$

Additionally, the HCM 2000 model can be then modified as follows:

$$
C_{m}=\left(-0.0004 v_{c}+1.1065\right) \times C_{2000}
$$

where $C_{m}$ is the entry capacity from the modified HCM 2000 model.

In this study, we thus validate the modified HCM 2000 model. As can be seen in Table 2, the modified HCM 2000 model provides a smaller value of relative error $(0.92 \%)$ and RMSD (12.79) than the HCM 2000 model (4.66\% and 48.17). Accordingly, the modified HCM 2000 model is proven outperform the HCM 2000 model. This finding successfully validates the feasibility of the modified HCM 2000 model.

\section{Conclusion}

Some studies asserted that the HCM 2000 model could over- or under- estimate singlelane roundabout entry capacity because an unfit assumption of headway distribution type is used. Accordingly, this study firstly analyses headway distributions based on field survey. It is found that the inverse Gaussian distribution is the most suitable distribution type of headway samples. According to this finding, this paper adjusts the HCM model by proposing a simulation based approach to estimate entry capacity. A linear relationship is thus established to represent the relationship between a capacity ratio of the simulationbased approach to the HCM 2000 model and conflicting flow. The linear function can be considered as a coefficient of the HCM 2000 model. It is believed that the modified HCM 2000 model outperforms the HCM 2000 model.

\section{Reference}

Bared, J. G. and Afshar, A. M., 2009. Using Simulation to Plan Capacity Models by Lane for Two- and Three-Lane Roundabouts. In Transportation Research Record: Journal 
of the Transportation Research Board, No. 2096, Transportation Research Board of the National Academies, Washington, D.C., 2009, pp. 8-15.

Bie, J., Lo, H. K. and Wong, S., 2012. Capacity Evaluation of Multi-lane Traffic Roundabouts. Journal of Advanced Transportation, Vol. 44, 2012, pp. 245-255.

Cowan, R. C., 1997. Useful Headway Models. Transportation Research, Vol. 9, 1997, pp. 371-375.

Dahl, J. and Lee, C., 2012. Empirical Estimation of Capacity for Roundabouts Using Adjusted Gap-Acceptance Parameters for Trucks. In Transportation Research Record: Journal of the Transportation Research Board, No. 2312, Transportation Research Board of the National Academies, Washington, D.C., 2012, pp. 34-45.

Diah, J. M., Rahman, M. Y. A., Adnan, M. A. and Khoo, H. L., 2011. Modeling the Relationship between Geometric Design and Weaving Section Flow Process of Conventional Roundabouts. ASCE Journal of Transportation Engineering, Vol. 137, 2011, pp. 980-986.

Flannery, A., 2001. Geometric Design and Safety Aspects of Roundabouts. In Transportation Research Record: Journal of the Transportation Research Board, No. 1751, Transportation Research Board of the National Academies, Washington, D.C., 2001, pp. 76-81.

Flannery, A. and Datta, T. K., 1997. Operational Performance Measures of American Roundabouts. Presented at the $76^{\text {th }}$ Annual Meeting of the Transportation Research Board, Washinton, D.C., 1997.

Fortuijn, L. G., 2009. Turbo Roundabouts Estimation of Capacity. In Transportation Research Record: Journal of the Transportation Research Board, No. 2130, Transportation Research Board of the National Academies, Washington, D.C., 2009, pp. 83-92.

Harders, J., 1968. Die Leistungsfähigkeit Nicht Signalgeregelter Städtischer Verkehrsknoten (Capacity of Unsignalized Urban Intersections). Straßenbau und Straßenverkehrstechnik, Heft 76. Hrsg.: Bundesminister für Verkehr, Abt. Straßenbau, Bonn, 1968.

Hellinga, B. and Sindi, A., 2012. Analytical Method for Estimating Delays to Vehicles Traversing Single-Lane Roundabouts as a Function of Vehicle and Pedestrian Volumes. In Transportation Research Record: Journal of the Transportation Research Board, No. 2912, Transportation Research Board of the National Academies, Washington, D.C., 2012, pp. 56-66.

Isebrands, H. and Hallmark, S., 2012. Statistical Analysis and Development of Crash Prediction Model for Roundabouts on High-Speed Rural Roadways. In Transportation Research Record: Journal of the Transportation Research Board, No. 2312, Transportation Research Board of the National Academies, Washington, D.C., 2012, pp. 3-13.

Jin, S., Qu, X. B. and Wang, D. H., 2011. Assessment of Expressway Traffic Safety Using Gaussian Mixture Model Based on Time to Collision. International Journal of Computational Intelligence Systems, Vol. 4, 2011, pp. 1122-1130.

Kittleson \& Associates. Modern Roundabouts., 2011. The Web Site: http://roundabouts.kittelson.com/Roundabouts Accessed on August 2011.

Meng, Q. and Qu, X. B., 2012. Estimation of Rear-End Vehicle Crash Frequencies in Urban Road Tunnels. Accident Analysis and Prevention, Vol. 48, 2012, pp. 254-263.

Mereszczak, Y., Dixon, M., Kyte, M., Rodegerdts, L. and Blogg, L., 1998. Including Exiting Vehicles in Capacity Estimation at Single-lane U.S. Roundabouts. In 
Transportation Research Record: Journal of the Transportation Research Board, No. 1988, Transportation Research Board of the National Academies, Washington, D.C., 2006, pp. 23-30.

Polus, A., Lazar, S. S. and Livneh, M., 2003. Critical Gap as a Function of Waiting Time in Determining Roundabout Capacity. ASCE Journal of Transportation Engineering, Vol. 129, 2003, pp. 504-509.

Qiu, T. Z. and Yin, D., 2011. Comparison of Macroscopic and Microscopic Simulation Models in Modern Roundabout Analysis. In Transportation Research Record: Journal of the Transportation Research Board, No. 2265, Transportation Research Board of the National Academies, Washington, D.C., 2011, pp. 244-252.

Qu, X., Ren, L., Wang, S., and Oh, E., 2014a. Estimation of entry capacity for single-lane modern roundabouts: A case study in Queensland, Australia. Journal of Transportation Engineering. 140 (7), 05014002.

Qu, X., Wang, S., and Zhang, J., 2015. On the fundamental diagram for freeway traffic: A novel calibration approach for single-regime models. Transportation Research Part B, 73, 91-102.

Qu, X., and Meng, Q., 2014. A note on hotspot identification for urban expressways. Safety Science. 66, 87-91.

Raff, M. S. and Hart, J. W., 1950. A Volume Warrant for Urban Stop Sign. Traffic Engineering and Control, Vol. 5, 1950, pp. 255-258.

Siegloch, W., 1973. Die Leistungsermittlung a Knotenpunkten Ohne Lichtsignalsteuerung (Capacity Estimation at Unsignalized Intersections). Straßenbau und Straßenverkehrstechnik, Heft 154. Hrsg.: Bundesminister für Verkehr, Abt. Straßenbau, Bonn, 1973.

Transportation Research Board (TRB). Highway Capacity Manual 2000.

Troutbeck, R., 1992. Estimating the Critical Acceptance Gap from Traffic Movements. Research Report, Vol. 92, 1992.

Turner, S., Wood, G., Hughes, T. and Singh, T., 2011. Safety Performance Functions for Bicycle Crashes in New Zealand and Australia. In Transportation Research Record: Journal of the Transportation Research Board, No. 2236, Transportation Research Board of the National Academies, Washington, D.C., 2011, pp. 66-73.

Wei, T., Grenard, J. L. and Shah, H. R., 2011. Developing Capacity Models for Local Roundabouts Streamlined Process. In Transportation Research Record: Journal of the Transportation Research Board, No. 2257, Transportation Research Board of the National Academies, Washington, D.C., 2011, pp. 1-9.

Wei, T. and Grenard, J. L., 2012. Calibration and Validation of Highway Capacity Manual 2010 Capacity Model for Single-Lane Roundabouts. In Transportation Research Record: Journal of the Transportation Research Board, No. 2286, Transportation Research Board of the National Academies, Washington, D.C., 2012, pp. 150-110.

Wong, S. C., 1996. On the Reserve Capacities of Priority Junctions and Roundabouts. Transportation Research Part B, Vol. 30, 1996, pp. 441-453.

Wu, N., 2012. Equilibrium of Probabilities of Estimating Distribution Function of Critical Gaps at Unsignalized Intersections. In Transportation Research Record: Journal of Transportation Research Board, No. 2286, Transportation Research Board of the National Academies, Washington, D.C., 2012, pp. 49-55. 